\title{
Positive behavioral support: Strategies for teachers
}

\author{
Michael B. Ruef \\ Family Connection \\ Beach Center on Families and Disabilities \\ University of Kansas
}

Cindy Higgins

Beach Center on Families and Disabilities

University of Kansas

\author{
Barbara J. C. Glaeser \\ Department of Special Education \\ University of Kansas
}

Marianne Patnode

Auburn High School

Auburn, WA 


\title{
Positive behavioral support: Strategies for teachers
}

\begin{abstract}
Positive behavioral support (PBS) is a comprehensive, research-based proactive approach to behavioral support that endeavors to generate comprehensive change for students with challenging behavior. It involves identifying the purpose of challenging behavior, teaching appropriate alternative responses that serve the same purpose as the challenging behavior, consistently rewarding positive behaviors and minimizing the rewards for challenging behavior, and minimizing the physiological, environmental, and curricular elements that trigger challenging behavior. Proven PBS strategies include altering the classroom environment, increasing predictability and scheduling, increasing choice making, adapting the curriculum, appreciating positive behaviors, and teaching replacement skills. Relevant sources for those interested in implementing PBS are presented.
\end{abstract}


Positive behavioral support (PBS) is a broad term that describes a comprehensive, researchbased, proactive approach to behavioral support aimed at producing comprehensive change for students with challenging behavior. This article describes what PBS is, the value of exploring why a student exhibits challenging behavior, and certain key PBS strategies teachers can implement in their classrooms. Finally, the article offers relevant resources for those interested in implementing PBS.

Teachers report that student behavior is their number one difficulty (Coates, 1989; Elam, Rose, \& Gallup, 1996; Merrett \& Wheldall, 1993). Both general and special education teachers also report that they aren't sufficiently trained to deal with the aggression, defiance--even violence-that they witness daily (Horner \& Diemer, 1992; Merrett \& Wheldall, 1993; Ruef, 1997; Sugai \& Horner, 1994), and see increasingly in children at younger ages ("The Discipline Problem," 1996). This despite the fact that $93 \%$ of teachers have participated in behavior inservices or workshops and another 38\% are taking college classes on behavior management (U.S. National Education Goals Panel, 1995).

The time required to implement a strategy is among the leading criteria teachers use to choose behavioral interventions (Martens, Witt, Elliott, \& Darveau, 1985; Weigle, 1997). Teachers favor trial-and-error interventions and immediately effective strategies (e.g., timeout) or isolated behavioral strategies suggested by fellow teachers rather than functional analyses and other databased intervention strategies because they find these too time-consuming (Kampwirth, 1988; Ruef, 1997; Snell, 1988). Teachers' lack of planning time, high student-to-staff ratio, and lack of administrative support to implement behavior changes in general have been cited as problems related to time (Ayres, Meyer, Erevelles, \& Park-Lee, 1994). Faced with an increasing number of students whose behavior impedes their own learning or the learning of others, teachers are left wondering if and how they will find time to provide positive behavioral support to the growing number of students who need it.

Yet teachers, especially more experienced teachers, do endorse proactive strategies and are comfortable with the premise of positive behavioral support (Alderman \& Nix, 1997; Johnson \& Pugach, 1990; Witt \& Robbins, 1985), a more time-intensive behavior model that requires teachers to determine what the problem is--where, when, how, and most importantly, why it happens (e.g., frustration, escape, desire for attention, boredom, control, etc.)--and then use strategies for teaching new behavioral skills, positive behavior appreciation, and environmental changes (Carr et al., 1994; Horner, Albin, \& O'Neill, 1996). This article explains what PBS is and how all teachers can implement certain key PBS components in their classrooms.

\section{WHAT IS POSITIVE BEHAVIORAL SUPPORT?}

Did you ever hear the phrase, "Treat the symptom, ignore the disease"? Many people handle discipline that way. They try to eliminate challenging behavior (usually with punishment) without looking into why the behavior occurred. PBS is different--even revolutionary--because it is based on determining not only what, where, when and how challenging behavior occurs, but also why. PBS operates under the premise that behavior is not random but that any persistent challenging behavior "works" for the student. Why can't Mark remain seated during math? Why 
does Richard bang his head repeatedly? Why is Anastasia off-task so much? And what purposes (functions) do these behaviors serve for Mark, Richard and Anastasia?

Challenging behaviors such as these do meet some basic needs for a student. Students who act out do get more attention, higher levels of physical contact, or escape from work. But while meeting their immediate needs, disruptive behavior (such as aggression) interferes with others, especially in inclusive settings. It can also endanger the person exhibiting it and others, upset staff, and contribute to a negative attitude toward people with disabilities. Thus, it does not meet anyone's long-term needs--the teacher's need to have a functional classroom; other students' need to be safe; and the need of students with challenging behavior to learn socially appropriate ways to meet their needs and become more independent.

PBS broadens intervention from one approach--reducing challenging behavior--to multiple approaches: changing systems, altering environments, teaching skills, and appreciating positive behavior. The goal in PBS is not to "eliminate" behavior. Rather, it is to understand the behavior's purpose so that the student can replace it with new, prosocial behaviors that achieve the same purpose (Carr et al, 1994; Horner et al., 1992). PBS helps students learn better ways to make their feelings and needs known. Everyone shares responsibility for the behavior.

PBS bears consideration for three reasons. First, we now know that simply suppressing a behavior by punishing a student is counterproductive. It may have the short-term effect of reducing behavior, but studies now show that punishing challenging behaviors without a schoolwide system of support is associated with increased aggression, vandalism, truancy, tardiness, and dropout (Mayer \& Sulzer-Azaroff, 1996; Walker, Colvin, \& Ramsey, 1995). Further, reactive approaches using punishment do not teach the student a skill to use in the future. Second, once teachers know why a student's behavior is occurring, they are in a much better position to teach a more appropriate way of responding, a way that will serve the longterm interests of both student and teacher. This behavioral approach dramatically differs from traditional behavior modification. It shifts the focus from "fixing" the student to "fixing" skill deficiencies, settings, and systems (see Table 1 for a comparison of traditional behavior modification and PBS). Lastly, PBS works and works well. In a synthesis of 109 published studies of individuals with disabilities and severe challenging behavior conducted between 1985 and 1996, Carr and his colleagues (1997) documented the unqualified success of PBS on reducing the incidence of challenging behavior.

\section{INITIATING PBS: ASSESSING A BEHAVIOR'S PURPOSE}

Ideally, before teachers initiate any PBS plan, they should put certain foundational blocks in place. These include establishing a collaborative team composed of persons who support a student, gathering/evaluating information about the purpose (function) of a student's behavior, and ensuring that both parents and teacher view a proposed plan as desirable and feasible. Gathering enough information to identify the challenging behavior (e.g., off-task) and then checking to make sure you are on target about the probable purpose of the behavior (e.g., to escape doing a task) constitutes the PBS cornerstone known as "functional assessment." 
More serious, long-standing behaviors that serve multiple purposes require in-depth, "Level 3" information gathering/evaluation (see Figure 1 for the various levels of information gathering/evaluation involved in functional assessments) with professional, trained support. Dangerous behaviors require an emergency plan. However, for many difficult behaviors (e.g., off-task, out-of-seat, noisy) that create constant demands for supervision or make the student stand out from others, provoking annoyance or embarrassment, the information gathering and evaluation process need not be long or arduous and can be accomplished in four steps.

1. Define the challenging behavior. The definition must be observable and highly descriptive of the behavior's appearance. "Mark is aggressive and runs from class," for example, is too vague and ambiguous. A better definition would be, "Mark will leave class or a designated activity area, often grabbing and damaging materials as he goes. If a staff person tries to keep him from leaving the area, he will strike out by grabbing, hitting, pulling hair, and/or kicking."

2. Identify the circumstances under which the behavior is both likely and unlikely to occur. The process of identifying these key circumstances may be either straightforward or involve varying amounts of detective work. Teachers can use the form in Figure 2 to identify times when challenging behavior might occur. Filling out this form helps reveal occurrence patterns associated with a particular time of day. Although Figure 2 uses halfhour increments, teachers may use larger or smaller increments as appropriate.

Challenging behaviors often do not follow orderly patterns. Instead of consistently resisting teacher requests or consistently throwing tantrums to get attention, a student may do very well for many days and then, under the usual conditions, display extreme challenging behaviors. Under these conditions, a teacher will have to investigate further. Discussions (with other teachers/ paraprofessionals), interviews (with parents and others), and direct observations will be necessary. Challenging behaviors may, for example, result from an occurrence or set of circumstances ("setting event") that the teacher is unable to directly observe. Allergic flare-ups, fluctuation in dosages of medication, disturbed sleep patterns, or changes in away-fromclassroom routines may trigger challenging behaviors in seemingly unpredictable or unexplainable ways. A checklist of items teachers may consider in gathering and evaluating information (especially physiological information) from parents, paraprofessionals, former teachers, and other school staff (e.g., the school nurse or counselor) is provided in Figure 3.

- 3. Determine the potential purpose(s) of the challenging behavior: Interviews and discussions, followed by direct observations of challenging behavior and the events happening before (triggering events or circumstances) and after the challenging behavior occurs (what the student achieves by the behavior), should help teachers determine a behavior's purpose. In addition, though, in as little as 10 to 15 minutes, teachers and paraprofessionals can complete The Motivational Assessment Scale (Durand \& Crimmins, 1992). This 16-item scale allows teachers to determine if a challenging behavior is motivated by social attention, escape, sensory feedback, tangibles, or a combination of these four. Remember, challenging behaviors do not happen repeatedly unless individuals periodically get something they want or avoid something they do not want. These purposes or "consequences" influence the challenging behavior. A "punisher" for a teacher may or may not be a "punisher" for a student. Teachers can never 
assume that a particular response (e.g., sending a student to the vice principal) will always be punishing with all students. For a student motivated by escape, being sent to the vice principal's office may, in fact, be reinforcing.

- 4. Evaluate the information and develop a hypothesis or "best guess" statement describing the relationship between the behavior and the student's environment. Statements such as, "Mark is aggressive and runs from the room (behavior is only vaguely described) because of his autism" (reason does not include purpose for behavior), should be replaced with specific statements based on observations that indicate how to change the environment to promote positive behavior. In general, functional assessment should be conducted at a level sufficient to describe the behavior in question, situations or predictors when the behavior is most likely to occur and not occur, and the behavior's function or purpose (O'Neill et al., 1997). For example, "Mark runs from the classroom or designated task areas to escape difficult tasks or learning situations. Escape from restraint is another reason for his behavior. When staff use restraint to keep him from leaving, trashing the room, or escorting him back to class, he will usually grab, hit, pull hair, and/or kick" (behavior is specifically described; reason includes purpose for behavior).

For many students, using any of these techniques enables teachers to view challenging behaviors in the context of why they are occurring. Focusing on why challenging behavior occurs, in turn, helps them decide what to do. "When prevention becomes the goal, as it should, the focus of intervention planning changes from what we might do to the child to what we might change about our own classroom practices" (Strain \& Hemmeter, 1997, p. 4).

\section{PBS STRATEGIES}

Teachers favor strategies that work for other teachers. Therefore, the following list is a description of six teacher-recommended, proactive, proven PBS strategies. Although they are most effective after functional assessment, the first five strategies can be implemented without or before such an assessment.

\section{Strategy 1: Alter the Classroom Environment}

Teachers can remove or modify environmental conditions within their classrooms that trigger challenging behaviors in a number of ways.

ACCOMMODATE INDIVIDUAL STUDENT ENVIRONMENTAL NEEDS. Information gathering may indicate that individual students' behavior is linked to environmental triggers. Students with attention-deficit/hyperactivity disorder (ADHD), for example, should be seated away from noisy, high-traffic areas. For students who are easily distracted, consider the use of a study carrel or a quiet learning center(s), clearly defined work areas that students can "cycle through" in a predictable sequence. Clearly defined work spaces (e.g., learning centers, study carrels, or carpet squares when children sit on the floor) help define each student's space. Deaf students or those who are hard of hearing should be placed near the front of the class. Consider also having light on your face for students who lip read and providing students with swivel chairs so they can more easily follow conversation. Portable bulletin boards and other devices may absorb distracting sounds. Some students--for example, students with autism--may be highly 
sensitive to bells, other loud noises, or other sensory stimuli such as particular perfumes, body odors, or particular colors. Providing a noise-sensitive student, for example, with earphones to wear during periods when the noise level is high will neutralize the effects of noise and thus minimize the likelihood of the behavior.

CONSIDER ROOM ARRANGEMENT. Learning centers need to have adequate space and be placed far enough apart so that activity and noise levels in one center are not disruptive to students in a neighboring center.

CONSIDER TRAFFIC PATTERNS. Too much or too little space may be problematic. Too much space may encourage young students to run, whereas too little space can lead to disruptive bumpings and knockings. (The checklist in Figure 3 includes some classroom environmental variables that may affect challenging behavior.)

\section{Strategy 2: Increase Predictability and Scheduling}

Uncertainty increases anxiety levels in most people. Consider your frustration when you lose your daily planner or when a lesson that you organized during the weekend time is interrupted by an unplanned fire drill. All students experience frustration, but especially those with learning challenges. Predictability of classroom routines is their "security blanket." According to Strain and Hemmeter (1997), "A classroom schedule that is well-designed and is implemented consistently may be the single most important factor in preventing challenging behaviors" (p. 5). Teachers who can develop or modify their routines to increase predictability will lessen anxieties (and challenging behaviors) for their students. There are several ways of doing this.

SCHEDULES. Create a routine daily schedule and make sure that students are aware of it. Middle or high school teachers may find a student version of a "weekly planner" useful in increasing predictability and appropriate behavior; elementary teachers may post their schedule prominently in their classroom. Prompting students to refer to their schedule and previewing what is about to happen at numerous times throughout the day is also important. Teachers can use these previews to clearly specify criteria and outcomes for activities. When students know what to do and when to do it, challenging behaviors are less likely to occur.

Teachers may need to establish separate individualized routines for students whose attention spans are limited or who are unable to sit for longer blocks of time. Teachers have successfully used "loop tapes"--tapes that automatically rewind and replay--to record daily schedules for students who have difficulty remembering or cannot use a written or visual calendar. Students with ADHD may need predictable time periods when they can leave their seats for some activity (e.g., collecting homework, distributing materials, taking attendance to the office) built into their schedules.

CHANGES. Planned or unplanned changes in daily schedules occur in every school. Assemblies or fire drills may shorten class schedules and alter bell schedules, therapists or paraprofessionals may be absent, busses may be late in arriving or leaving. Preparing students about how these changes will affect their day lessens anxiety. Students with autism, for example, appreciate knowing any schedule changes. Students who receive therapy on a regular basis appreciate 
knowing when their therapist is ill, how long the therapist will be gone, and who will provide therapy in the interim. Teachers can present this information in a format best suited to the student's learning style. A picture of the therapist, for example, can be removed from a student's schedule and replaced with a picture symbol representing "ill" for the number of anticipated sick days.

TRANSITIONS. Alerting students before transitions from one activity to another can increase the likelihood of appropriate behavior. These signals give students the opportunity to finish what they are doing before having to put it away. Teachers can choose from a variety of signals; different students may need different kinds (e.g., auditory, tactile, or visual). Many students, for example, respond well to taped music of various lengths (e.g., 2 minutes = approximately one song, 5 minutes = approximately two songs, 10 minutes = approximately four songs) to signal the end of various activities. As students repeatedly hear a particular song or series of songs, they know that an activity is ending within a given period of time. Minimizing waiting periods or providing other activities for early finishers also promotes appropriate behavior. When students are engaged with people or materials, they are less likely to exhibit challenging behaviors.

\section{Strategy 3: Increase Choice Making}

Many people with disabilities (especially students with limited motor skills, verbal skills, or challenging behaviors) are not provided with opportunities to make significant choices in their daily lives. They are often told what tasks they must perform, with whom they may interact, and what rewards they may have. Because these students have difficulty expressing choice, choice making should be systematically taught and monitored in the same ways as other skills (Brown \& Snell, 1993).

Providing students with challenging behavior with opportunities to make choices is another way of teaching them that they can influence others without having to resort to challenging behavior. Providing choice does not mean allowing students to control situations in which they pose a danger to themselves or others. Nor does it mean allowing them to do anything that they want to do. It does mean permitting students to make choices as part of an approach aimed at increasing student's inclusion, productivity, and independence. By empowering students to make choices, teachers can help lessen student feelings of powerlessness. Teachers, parents, and students together can create a list of choices, but the student, whenever possible, makes the final selection. Teachers might consider the following checklist in offering choices to a student with challenging behavior (Carr et al., 1994):

- Assess choice-making skills

- Identify types and extent of choices available

- Provide opportunities for choice whenever appropriate and feasible

- Create options that are related to factors controlling challenging behavior (e.g., if a student is motivated by escape from task demands, provide an array of tasks from which to choose; if motivated by attention, provide opportunities for interaction such as teachers, aides, or peer tutors, with whom the student can choose to interact)

- Allow person to choose one of the available options and honor that choice 
- Honor choices not offered unless they would result in disruption or prevent important goals from being met

- Provide natural consequences for failure to make choices (e.g., you choose for the student)

- Embed choice into activity or task when possible

- Monitor for success

\section{Strategy 4: Make Curricular Adaptations}

Curricular adaptations are modifications made to enhance a student's performance in completing activities and to reduce the likelihood of challenging behaviors. Why spend the extra time making such adaptations? Ferro, Foster-Johnson, and Dunlap (1996) found a significant relationship between curricular activities and students' positive and negative behaviors. Activities/tasks that (a) students intended to use at home or in the community, (b) reflected students' interests, and (c) were age appropriate were significantly associated with positive behavior, whereas activities/tasks that did not reflect these characteristics were associated with challenging behaviors. In addition, researchers found that adjustments in the difficulty level, length, or pace of an activity heightened levels of motivation and reduced levels of off-task and disruptive behaviors in students with disabilities (G. Dunlap \& Plienis, 1991; Robbins \& Dunlap, 1992).

What can a teacher do to adapt the curriculum when observation suggests that the existing curriculum is prompting challenging behavior? Consider the following four elements.

1. Think about the nature of the assigned task/activity and the way it is presented. Is the task or activity of high or low interest? Too easy or too difficult? Too long or too short? Too fast or slow paced? A quick checklist teachers can complete in assessing curriculum/instruction is provided in Figure 3.

2. Adjust the nature of the task/activity. Presenting material using different modalities (e.g., auditory, visual, tactile) or shortening instruction to highly structured blocks of 20 minutes or less have proved successful. Task variation, or interspersing previously learned tasks among new tasks, is another strategy. Especially when a new skill is relatively difficult for a student, studies have shown that constant task strategies (massed trials) often result in waning motivation and performance and increase off-task behaviors (Winterling, Dunlap, \& O'Neill, 1987). By interspersing previously mastered tasks, teachers ensure variety in their lessons by incorporating different types of instruction rather than the same task repeatedly. Task variation also ensures a level of student competence by rewarding each successful performance of the already mastered task as well as successes with the new task.

Teachers might have initial concerns about using their limited instructional time with techniques that slow the pace of instruction or frequently reviewing previously learned material. At least for relatively difficult tasks, research has shown that frequent presentation of previously learned tasks is a more efficient teaching strategy than the constant task (or massed trials) approach (G. Dunlap \& L. K. Dunlap, 1987). 
A third way to adjust the nature of the task/activity is by taking advantage of student interests and preferred activities. This does not mean spoiling students by always letting them engage in preferred activities. It does, however, mean planning preferred activities to occur consistently and predictably throughout each day and week. If, for example, a student is highly motivated by computer technology, opportunities to complete tasks on the computer should serve as anchors in the student's daily and weekly schedule. In addition, nonpreferred tasks (e.g., learning multiplication tables) can be "embedded" within the context of a preferred task or activity (e.g., using an animated computer software program to teach multiplication).

3. Adjust the method of presentation/monitoring. There are a number of ways teachers can adjust methods of presentation/monitoring of learning tasks or activities to meet the diverse needs of students. Two that deserve special attention for students with challenging behavior are direct instruction and self-monitoring.

Direct instruction is an approach emphasizing group instruction and face-to-face instruction using carefully sequenced lessons. Research supports the use of direct instruction for hard-toteach students (Adams \& Englemann, 1996; Lloyd, Forness, \& Kavale, 1998; Stein, Carnine, \& Dixon, 1998) and seems particularly applicable to students with challenging behaviors.

Maximizing academic learning time and providing a structured learning environment limits the opportunities students have to disrupt the classroom and/or exhibit challenging behavior. There is no single type of direct instruction, but many such programs have the following characteristics:

- Well-scripted and preplanned teacher presentations

- Fast-paced presentations

- Use of small groups to maximize student responding

- Oral group responding to monitor learning of all students

- Individual mastery tests

- Student motivation maintained by teacher praise/reinforcement/encouragement

- Immediate error correction (Rhode, Jenson, \& Reavis, 1997)

Self-monitoring is a powerful, easily implemented intervention. It has been used successfully with students ranging from average achievers (Lloyd, Landrum, \& Hallahan, 1996) to students with moderate and severe disabilities as a technique to decrease disruptive behaviors and improve academic skills (L. K. Dunlap \& G. Dunlap, 1989; Quinn, Swaggart, \& Myles, 1994), on-task responding (Rhode, Morgan, \& Young, 1983; Swaggart, 1998), and articulation (Koegel, Koegel, Van Voy, \& Ingham, 1988). Self-monitoring is accomplished by teaching students to identify and record occurrences of behavior and then rewarding them both for successful selfmonitoring and for decreases in challenging behaviors. Self-monitoring involves (a) defining the target behavior, (b) identifying preferred reinforcers, (c) designing a self-monitoring device/method, (d) teaching the student to use the device, and (e) fading the use of the device. The advantages of self-monitoring include increases in students' independent responding, more generalization and durability of behavior change, and reduced teacher supervision.

Other strategies that teach self-control by increasing student awareness of how behavior affects learning include observational learning and self-instruction (Swaggart, 1998). 
4. Provide peer support. Although peer support depends on a "personality match" and may not work in every instance, it has proved successful for students with challenging behavior. Two types of peer support are peer tutoring and the PALS approach.

Peer tutoring instruction of one student by another for academic or social support has the great advantage of allowing students to respond frequently and demonstrate whether they have acquired important information and skills. For example, researchers have found that students have limited opportunities to respond to academic tasks during the school day (Durrer \& McLaughlin, 1995). Peer tutors increase student opportunities to respond. In addition, researchers have found that peer tutors use more age-appropriate vocabulary and examples than the teacher does, can identify with the frustration of learning material, and tend to be more direct and supportive than adults (Good \& Brophy, 1990). Peer tutoring can provide structured practice or review, monitoring of learning, and reinforcement of teacher-directed instruction. Peers can take notes using carbon paper if a "buddy" with ADHD has problems listening and taking notes. A copy will then be available for the buddy and the stress of listening and writing will be reduced.

Teachers have also found the PALS approach particularly useful for teaching social skills to younger children. This approach is based on arranging the environment; it Pairs typical learners with those with disabilities during activities, Arranges for adults to be absent from the activity or reduce their rate of interaction, Limits the number and variety of materials available during activities (to those that occasion interaction), and Structures the activity so that children work toward a cooperative goal and understand their role in achieving the goal. Using this approach, teachers can arrange a number of play areas with different materials/devices to set the occasion for different child behaviors. Such diverse play areas have been shown to increase the survival skills and experiences children acquire through play (Chandler, 1996).

\section{Strategy 5: Appreciate Positive Behaviors}

Ideally, students will do the "right" thing in the "right" way with the "right" attitude. Actually, that's just how it is for a lot of people. They don't need to be encouraged with constant praise, trinkets, or future promises. Their reward is the activity or behavior itself. However, many students don't have the social, learning, or behavioral skills that will help them thrive in the classroom or community.

TAKE ADVANTAGE OF POSITIVE REINFORCEMENT. Simply put, positive reinforcement teaches a person to act in a certain way by rewarding that person for correct behavior. The theory is that if someone gets a reward for an action, then that person is more likely to do that action again. Positive reinforcement, which has been studied in great detail in the last 25 years, has proved to be an important part of the learning process (Repp, Dietz, \& Dietz, 1976; Wolf, Hanley, King, Lachowicz, \& Giles, 1970). To encourage positive behavior, figure out the exact behavior that would benefit the student and the people around the student. Start with easier skills and break down more complex tasks into achievable steps. You may also consider teaching selfmonitoring skills that will support more durable behavior changes and decrease the amount of adult supervision required. 
DETERMINE THE RIGHT REWARD. Make sure you have the right rewards: Training will have little effect without a good reinforcer. Decide what the student--not you--views as rewards. One person's preference is not the same as another's. Typical rewards include food, drink, sensations (listening to music), materials (stickers, badges, certificates), activities (working on a preferred activity or with a special friend), and privileges (extra free time, new seating arrangement). A good way to start is to ask the student what would be a reward for him or her. If the student is unable to verbalize, try offering several choices. Do this several times to make sure.

If a reward can be paired with a natural reinforcer, all the better. For example, for a socially motivated student, a soda pop (extrinsic reward) might be paired with social interactions that naturally occur (intrinsic reward) in the course of performing small jobs such as taking attendance to the office. This pairing ultimately allows the behavior (task completion) to be maintained in a natural or intrinsic way (Carr et al., 1994; Green et al., 1988; Snell \& Brown, 1993).

Praise, too, must be used correctly. Use words of encouragement, appreciation, and affection, as well as physical expressions, such as hugs, pats, and smiles. But be careful not to turn praise into a verbal reward that leaves people feeling forced, patronized, or bribed to do a task.

REDUCE REWARDS OVER TIME. At first, rewards should be given immediately and frequently when the person exhibits proper behavior. (During this time, ignore challenging behavior unless it is dangerous or destructive.) In fact, you may initially set up a learning situation in which rewards come at a rapid pace--even every minute, as researchers have done in studies--to teach desired behavior. Later, rewards should be given less frequently as the behavior becomes learned. Alberto and Troutman (1990) have pointed out that the more you reward someone for a task, the less interest the person will have for the task itself. Rewards, too, are a form of control. Nobody likes to be manipulated. Remember, your goal is to have the behavior or skill be a reward in itself.

KEEP REWARDS INTERESTING AND THE STUDENT CONFIDENT. Rewards will probably have to be changed at different times to keep them desirable. For certain students, you also can use tokens, points, or other scoring devices that the person will collect to trade in for a larger reward. Lastly, to encourage good behavior, always indicate your confidence in the student's abilities. This lets the student know you recognize his or her good intentions and that you believe he or she can learn and grow.

\section{Strategy 6: Teach Replacement Skills}

Many challenging behaviors occur because the student does not know a more appropriate way to achieve an important outcome. By teaching appropriate, alternative responses that serve the same purpose as the challenging behavior, teachers can reduce the incidence of challenging behavior and increase the skill level of their students. Unlike the first five strategies outlined here, which can simply be implemented as "best practices" without knowledge of a behavior's purpose, teaching an alternative response depends on knowing the purpose(s) of the challenging behavior; this is determined during the functional assessment. Many times the alternative responses taught 
are communicative in nature (e.g., appropriate ways to get attention/assistance, request a break or change of activity, etc.) (Carr et al., 1994; Horner et al., 1996). Suppose a student, Mark, runs from the classroom or designated task areas to escape difficult tasks or learning situations. Suppose also that the grabbing, hitting, hair pulling, and/or kicking he does when staff use restraint to keep him from leaving, trashing the room, or escorting him back to class, serves the additional purpose of prolonging attention from teachers and peers. In this instance, replacement behaviors might involve three areas. One place to start might be with social skills. Mark doesn't know how to "connect" with others. The PALS program might help him learn to greet people, express positive statements, share enjoyable activities, and meet some needs of friends while they meet some of his. In addition, because Mark is angry with others for not giving him attention, he needs to learn to recognize and appropriately express his anger (through role playing, dialogue, verbal rehearsal, modeling, and eliciting feelings) and diffuse it through direct communication and stress management techniques such as deep breathing. In addition, Mark and his teacher need to work out a system that works for both of them whereby Mark can communicate that a task or activity is too difficult. Finally, all these strategies need to be implemented together with necessary environmental and/or curricular changes (e.g., Mark has a safe but otherwise nonreinforcing place to calm down and difficult tasks are shortened or embedded within easier segments) and positive behavior needs to be reinforced.

Although some social skills training may be appropriate for the classroom (e.g., all students could benefit), other training may be more appropriately conducted outside the classroom by a counselor, psychologist, or other school support person.

Finally, teachers must consider both the effectiveness and the efficiency of the alternative behaviors they choose to teach (Carr et al., 1994; Horner et al., 1996). In the case of Mark, running from the room took relatively little time or energy and produced the "double-barrel" effect of allowing him to escape from an overly difficult assignment and drawing the attention of both teacher and peers. To be successful, replacement behaviors must be as or more effective and efficient for Mark as running from the room. Proactively adapting the difficulty level of his assignments, allowing him (at least initially) to move to a calm-down area, together with positive reinforcement (attention) for academic and social successes equal to or greater than the attention received for running from the room (while minimizing the attention for challenging behavior), should produce positive effects.

\section{$\underline{\text { SUMMARY }}$}

PBS involves four main steps:

1. Identifying the purpose of challenging behavior

2. Teaching appropriate alternative responses that serve the same purpose as the challenging behavior

3. Consistently rewarding positive behaviors and minimizing the rewards for challenging behavior

4. Minimizing the physiological, environmental, and curricular factors that trigger challenging behavior. 
PBS calls for proactivity and a reevaluation of the reactive "quick-fix" method of intervening. It encourages teachers (ideally as part of a collaborative team) to take time "up front" to answer the question, "Why is my student behaving like this?" Not a lock-step approach, it looks at both individual student and teacher needs. A good PBS plan is one that works for both. It takes advantage of sound educational best practice and results in increased teaching and learning time, increased productivity, inclusion, and independence. PBS does not mean that teachers must become behavioral experts. Rather, PBS provides a means by which they may be able to become more clear, more predictable, more responsive, and more creative. 
Table 1. Comparison of Traditional Behavior Management and Positive Behavioral Support

\section{Traditional behavior management}

Views individual as "the problem"

Attempts to "fix" individual

Extinguishes behavior

Sanctions aversives

Takes days or weeks to "fix" a single behavior

Implemented by a behavioral specialist often in atypical settings

Often resorted to when systems are inflexible

\section{Positive behavioral support}

Views systems, settings, and skill deficiencies as "the problem"

Attempts to "fix" systems, settings, and skills

Creates new contacts, experiences, relationships, and skills

Sanctions positive approaches

Takes years to create responsive systems, personalized settings, and appropriate/empowering skills Implemented by a dynamic and collaborative team using person-centered planning in typical settings

Flourishes when systems are flexible 
Figure 1. The three levels of information gathering in conducting a functional assessment.

Level 1: Information Gathering to Identify Challenging Behavior and its Purposes

- Talk to individual with challenging behavior and those that know the individual best

- Conduct interviews, questionnaires and rating scales (e.g., The Motivational Assessment Scale)

Level 2: Direct Observation

- Record when a challenging behavior occurs, what happened just before the behavior, what happened after

- Record perception as to the function of the behavior

- Collect 10-15 instances of the behavior

- Look for a pattern

- Do observations confirm Level 1 information?

Level 3: Functional Analysis Manipulations[*]

- Systematically change potential controlling factors (consequences, structural variables, i.e., task difficulty or length)

- Observe effects on a person's behavior

Use Levels 1, 2, and possibly 3, to answer the following questions:

- What challenging behaviors cause concern?

- What events, times, or situations predict when the behavior will occur?

- What events, times, or situations predict when the behavior will not occur?

- What consequences maintain the challenging behavior (what does the person "get out" of the behaviors, e.g., attention, escape, preferred items)?

- What appropriate behaviors could produce the same result?

- What can be learned from previous behavioral support efforts about strategies that are ineffective, partially effective, or effective for only a short time?

* Note: As these determinations involve creating situations that will reduce, eliminate or provoke the challenging behavior to test whether the hypothesis (educated guess) is correct, they should be conducted with caution. Especially when creating situations that may provoke challenging behaviors, these manipulations should be conducted by a person trained in behavior analysis. 
Figure 2. Form for discovering occurrence patterns.

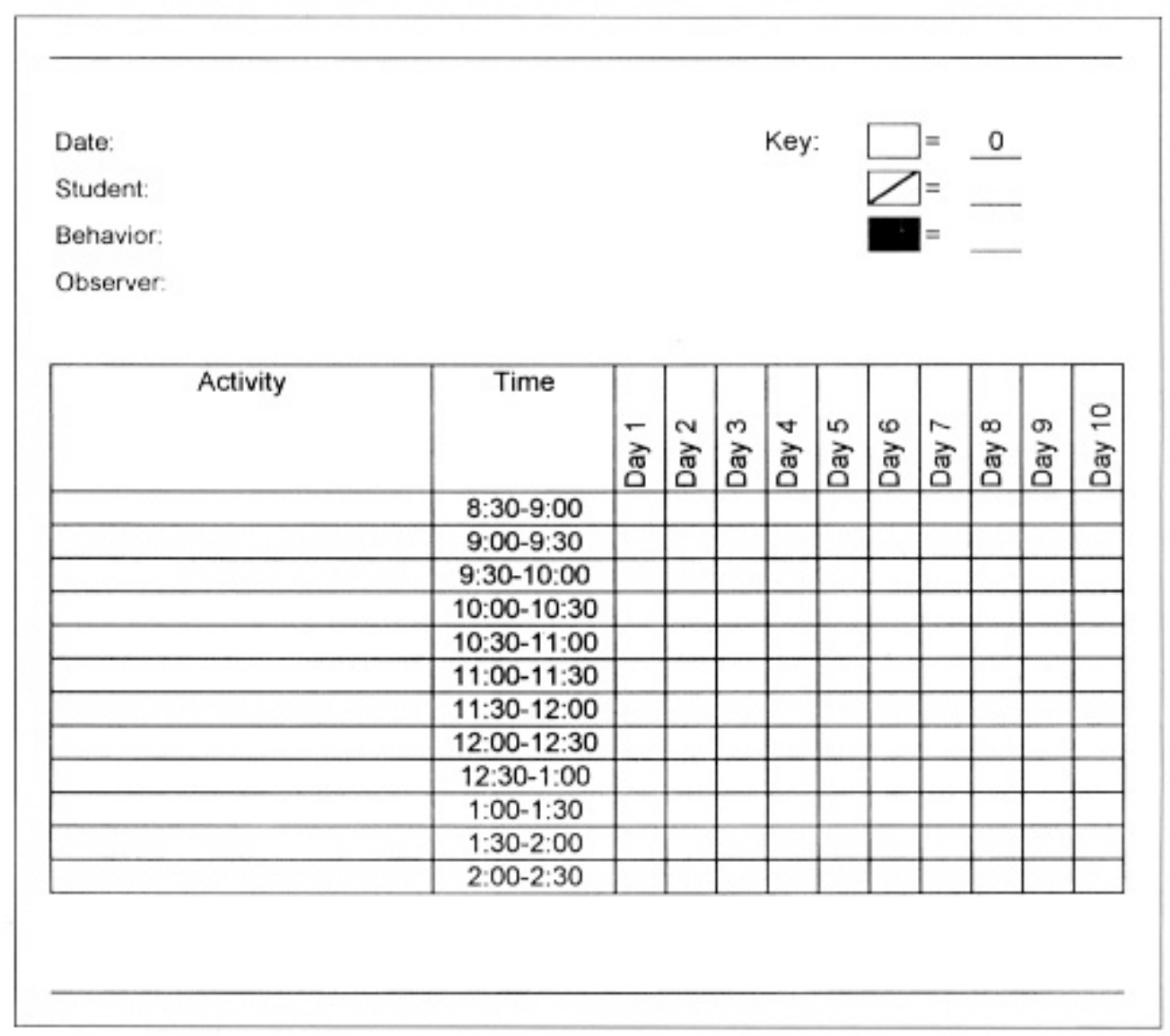


Figure 3. Behavior sample variables checklist.

\begin{tabular}{|c|c|}
\hline Physiological Factors & Curriculum and Instruction \\
\hline 口 Sickness/allergies & Few opportunities to make choices \\
\hline D Medication side effects & $\square$ Schedule unpredictability \\
\hline$\square$ Fatigue & $\square$ Inadequate assistance \\
\hline$\square$ Hungerithirst/diet & $\square$ Unclear activity directions \\
\hline 口 Arousal (e.g, fight, missed bus) & $\square$ Lack of communication opportunities \\
\hline D Sleep patterns & $\square$ Difficult activity \\
\hline Sensory sensitivities (e.g., odors, noise, colors) & $\square$ Activity too long \\
\hline \multicolumn{2}{|l|}{ Classroom Environment } \\
\hline & $\square$ Activity perceived as irrelevant or useless \\
\hline$\square$ High noise levels & $\square$ Staffing support \\
\hline Uncomfortable temperature & \\
\hline$\square$ Over-or understimulation & \\
\hline ב Poor seating arrangement & \\
\hline J Frequent disruptions & \\
\hline
\end{tabular}




\section{REFERENCES}

Adams, G. L., \& Englemann, S. E. (1996). Research on direct instruction: Twenty-five years beyond Distar. Seattle: Educational Achievement Systems.

Alberto, P. A., \& Troutman, A. C. (1990). Applied behavior analysis for teachers (3rd ed.). Columbus, OH: Merrill.

Alderman, G. L., \& Nix, M. (1997). Teachers' intervention preferences related to explanations for behavior problems, severity of the problem, and teacher experience. Behavior Disorders, 22, 87-95.

Ayres, B. J., Meyer, L. H., Erevelles, N., \& Park-Lee, S. (1994). Easy for you to say: Teacher perspectives on implementing most promising practices. Journal of the Association for Persons with Severe Handicaps, 19, 84-93.

Brown, F., \& Snell, M. E. (1993). Measurement, analysis, and evaluation. In M. E. Snell (Ed.), Instruction of students with severe disabilities (4th ed., pp. 152-183). New York: Macmillan.

Carr, E. G., Horner, R. H., Turnbull, A. P., Marquis, J. G., Magito-McLaughlin, D., McAtee, M. L., Smith, C. E., Ryan, K. A., Ruef, M. B., \& Doolabh, A. (1997). Positive behavioral support as an approach for dealing with problem behavior in people with developmental disabilities: A research synthesis. Unpublished manuscript, State University of New York, Stony Brook.

Carr, E. G., Levin, L., McConnachie, G., Carlson, J. I., Kemp, D. C. \& Smith, C. E. (1994). Communication-based intervention for problem behavior: A user's guide for producing positive change. Baltimore: Brookes.

Chandler, L. K. (1996). Strategies to promote physical, social, and academic integration in mainstream kindergarten programs. In G. Stoner, M. R. Shinn, \& H. M. Walker (Eds.), Interventions for achievement and behavior problems (pp. 269-288). Bethesda, MD: National Association of School Psychologists.

Coates, R. D. (1989). The Regular Education Initiative and opinions of regular classroom teachers. Journal of Learning Disabilities, 22, 532-536.

The discipline problem--And ways to deal with it. (1996,October). CEC Today, 3(4), 1-5.

Dunlap, G., \& Dunlap, L. K. (1987,Spring). Using task variation to motivate handicapped students. Teaching Exceptional Children, 19(3), 16-19.

Dunlap, G., \& Plienis, A. J. (1991). The influence of task size on the unsupervised task performance of students with developmental disabilities. Education and Treatment of Children, 14(2), 85-95. 
Dunlap, L. K., \& Dunlap, G. (1989). A self-monitoring package for teaching subtraction with regrouping to students with learning disabilities. Journal of Applied Behavior Analysis, 22, 309314.

Durand, V. M., \& Crimmins, D. B. (1992). The motivational assessment scale. Topeka, KS: Monaco \& Associates.

Durrer, B., \& McLaughlin, T. F. (1995). The use of peer tutoring interventions involving students with behavior disorders. B. C. Journal of Special Education, 19(1), 20-27.

Elam, S. M., Rose, L. C., \& Gallup, A. M. (1996). The third Phi Delta Kappa poll of attitudes toward the public schools. Phi Delta Kappan, 78, 244-250.

Ferro, J., Foster-Johnson, L., \& Dunlap, G. (1996). Relation between curricular activities and problem behaviors of students with mental retardation. American Journal on Mental Retardation, 101, 184-194.

Good, T. L., \& Brophy, J. E. (1990). Educational psychology: A realistic approach (4th ed.). Reading, MA: Addison-Wesley.

Green, C. W., Reid, D. H., White, L. K., Halford, R. C., Brittain, D. P., \& Gardner, S. M. (1988). Identifying reinforcers for persons with profound handicaps: Staff opinion versus systematic assessment of preferences. Journal of Applied Behavior Analysis, 21, 31-43.

Horner, R. H., Albin, R. W., \& O'Neill, R. E. (1996). Supporting students with severe intellectual disabilities and severe challenging behaviors. In G. Stoner, M. R. Shinn, \& H. M. Walker (Eds.), Interventions for achievement and behavior problems (pp. 269-288). Bethesda, MD: National Association of School Psychologists.

Horner, R. H., \& Diemer, S. M. (1992). Educational support for students with severe problem behaviors in Oregon: A descriptive analysis from the 1987-1988 school year. Journal of the Association for Persons with Severe Handicaps, 17, 154-169.

Johnson, L. J., \& Pugach, M. C. (1990). Classroom teachers' views of intervention strategies for learning and behavior problems: Which are reasonable and how frequently are they used? The Journal of Special Education, 24, 69-84.

Kampwirth, T. J. (1988). Behavior management in the classroom: A self-assessment guide for teachers. Education and Treatment of Children, 11, 286-293.

Koegel, R. L., Koegel, L. K., Van Voy, K., \& Ingham, J. C. (1988). Within-clinic versus outsideof-clinic self-monitoring of articulation to promote generalization. Journal of Speech and Hearing Disorders, 53, 392-399.

Lloyd, J. W., Forness, S. R., \& Kavale, K. A. (1998). Some methods are more effective than others. Intervention in School and Clinic, 33, 195-200. 
Lloyd, J. W., Landrum, T. J., \& Hallahan, D. P. (1996). Self-monitoring applications for classroom intervention. In G. Stoner, M. R. Shinn, \& H. M. Walker (Eds.), Interventions for achievement and behavior problems (pp. 201-213). Bethesda, MD: National Association of School Psychologists.

Martens, B. K., Witt, J. C., Elliot, S. N., \& Darveau, D. (1985). Teacher judgments concerning the acceptability of school-based interventions. Professional Psychology: Research and Practice, 16, 191-198.

Mayer G. R., \& Sulzer-Azeroff, B. (1996). Interventions for vandalism. In G. Stoner, M. R. Shinn, \& H. M. Walker (Eds.), Interventions for achievement and behavior problems (pp. 559580). Bethesda, MD: National Association of School Psychologists.

Merrett, F., \& Wheldall, K. (1993). How do teachers learn to manage classroom behavior? A study of teachers' opinions about their initial training with special reference to classroom behavior management. Educational Studies, 19, 91-105.

O'Neill, R. E., Horner, R. H., Albin, R. A., Sprague, J. R., Storey, K., \& Newton, J. S. (1997). Functional assessment and program development for problem behavior: A practical handbook. Pacific Grove, CA: Brooks/Cole.

Quinn, C., Swaggart, B. L., \& Myles, B. S. (1994). Implementing cognitive behavior management programs for persons with autism: Guidelines for practitioners. Focus on Autistic Behavior, 9(4), 1-13.

Repp, A. C., Dietz, S. M., \& Dietz, D. E. (1976). Reducing inappropriate behaviors in classrooms and individual sessions through DRO schedules of reinforcement. Mental Retardation, 14, 11-15.

Rhode, G., Jenson, W. R., \& Reavis, H. K. (1997). The tough kid book. Longmont, CO: Sopris West.

Rhode, G., Morgan, D. P., \& Young, K. R. (1983). Generalization and maintenance of treatment gains of behaviorally handicapped students from resource rooms to regular classrooms using self-evaluation procedures. Journal of Applied Behavior Analysis, 16, 171-188.

Robbins, F. R., \& Dunlap, G. (1992). Effects of task difficulty on parent teaching skills and behavior problems of young children with autism. American Journal on Mental Retardation, 96, 631-643.

Ruef, M. B. (1997). The perspectives of six stakeholder groups on the challenging behavior of individuals with mental retardation and/or autism. Unpublished doctoral dissertation, University of Kansas, Lawrence.

Snell, M. E. (1988). Curriculum and methodology for individuals with severe disabilities. Education and Training in Mental Retardation, 23, 302-314. 
Snell, M. E., \& Brown, F. (1993). Instructional planning and implementation. In M. E. Snell (Ed.), Instruction of students with severe disabilities (4th ed., pp. 99-151). New York: Macmillan.

Stein, M., Carnine, D. \& Dixon, R. (1998). Direct instruction: Integrating curriculum design and effective teaching practice. Intervention in School and Clinic, 33, 227-234.

Strain, P. S., \& Hemmeter, M. L. (1997). Keys to being successful when confronted with challenging behaviors. Young Exceptional Children, 1(1), 2-8.

Sugai, G., \& Horner, R. H. (1994). Including students with severe behavior problems in general education settings: Assumptions, challenges, and solutions. In J. Marr, G. Sugai, \& G. Tindal (Eds.), The Oregon Conference Monograph, 6, 109-120.

Swaggart, B. L. (1998). Implementing a cognitive behavior management program. Intervention in School and Clinic, 33, 235-238.

U.S. National Education Goals Panel. (1995). National goals report. Vol. I: National data. Washington, DC: U.S. Department of Education.

Walker, H. M., Colvin, G., \& Ramsey, E. (1995). Antisocial behavior in school: Strategies and best practices. Pacific Grove, CA: Brooks/Cole.

Weigle, K. (1997). Positive support as a model for promoting educational inclusion. Journal of the Association for Persons with Severe Handicaps, 22(1), 36-48.

Winterling, V., Dunlap, G., \& O'Neill, R. E. (1987). The influence of task variation on the aberrant behaviors of autistic students. Education and Treatment of Children, 10(2), 105-119.

Witt, J. C., \& Robbins, J. R. (1985). Acceptability of reductive interventions for the control of inappropriate child behavior. Journal of Abnormal Child Psychology, 13, 59-67.

Wolf, M. M., Hanley, E. L., King, L. A., Lachowicz, J., \& Giles, D. K. (1970). The timer- game: A variable interval contingency for the management of out-of-seat behavior. Exceptional Children, 37, 113-117. 